\title{
Good family function decrease internet addiction and increase academic performance in senior high school students
}

\author{
I Putu Belly Sutrisna', \\ I Gusti Ayu Endah Ardjana', \\ Supriyadi Supriyadi², \\ Lely Setyawati'
}

Departments of Psychiatry' and Psychology2, Faculty of Medicine, Udayana University/ Sanglah General Hospital

Bali, Indonesia

\begin{abstract}
Background: A good The Internet gives excellent benefits for education. Uncontrolled internet use causes internet addiction may cause a poor outcome, such as academic failure. Family functions hypothetically correlate with internet addiction and academic performance in adolescents at school. The research aims to see the correlations among family function with internet addiction and academic performance in adolescents at senior high school.
\end{abstract}

Method: Participants consisted of 305 adolescents from public senior high school students aged 14-18 years old. This research is using an analytical, cross-sectional method. The family function was assessed by the Family Assessment Device-Indonesian version (FAD-Ina). Internet addiction was assessed with Internet addiction Test Indonesian version (IAT-Ina). The student's academic performance was obtained from the school report card at that time.

Results: The result of this research shows that $76.4 \%$ of senior high school students have an internet addiction. The family function had a positive correlation and significant result with internet addiction $(\mathrm{R}=0.336, \mathrm{p}<0.05)$. The family function had a negative correlation and significant result with academic performance $(\mathrm{R}=0.176, \mathrm{p}<0.05)$. Internet addiction had a positive correlation and significant result with academic performance $(\mathrm{R}=0.128, \mathrm{p}<0.05)$. Good family function in adolescents has four times decrease for internet addiction risk compared with bad family function $(\mathrm{OR}=4.290)$.

Conclusion: This research shows that there was a $76.4 \%$ prevalence of internet addiction in adolescents at senior high school. A good family function can decrease internet addiction and increase academic performance in the adolescent. Good family function decreased internet addiction risk four times.

Keywords: family function, internet addiction, school report

\section{Introduction}

The Internet is used by most people to perform various activities of life. The discovery of the internet has many benefits that can change the world, becoming almost instantaneous, especially in the field of information, entertainment, communication, and transaction. But on the other hand, the internet also causes a lot of mental health problems, one of which is internet addiction.

Internet becomes more easily accessible from anywhere, with excessive and uncontrolled use causing pathological behavior called internet addiction.1 The increase in internet users is likely to lead to an increase in cases of internet addiction throughout the world, especially in Indonesia. Internet addiction is one of the adverse effects of internet development. Most population and internet users in the community are adolescents, so they are at high risk for internet addiction. 
Many adolescents, as the backbone and expected future of a nation, experienced internet addiction. Internet addiction makes them a person with impaired physical, mental, and social and led to the destruction of the nation's future. The rapid growth of internet users makes better communication, information, and social systems but excessive uncontrolled use because of internet addiction. ${ }^{2}$ One of the negative results of internet addiction is a decrease in physical and mental health, poor academic achievement, and interpersonal relationship problems became a highlighted topic at the Diagnostic and Statistic of Mental Disorder (DSM) 5 sub-section III. ${ }^{3}$

Adolescents who sit in high school have a higher risk of experiencing internet addiction because, at this age, they have started to separate from their parents and get along with their peers. They really need the role of parents as head of the family in providing parenting until adulthood. A good family is a sound basis for controlling the growth and development of children in the future.

The family role is very important in the incidence of internet addiction in adolescents. A good functioning family develops a mature adolescent. The opposite happens with a poorly functioning family with many negative impacts on adolescents; one of them is internet addiction that develops an immature personality. The family role is a fixed pattern of behavior in which every member of the family gets family functions and their needs. ${ }^{4}$ One of the causes of internet addiction is a poor functioning family. ${ }^{5}$

This study aims to discover how family function creates adolescents with internet addiction, how it affects academic performance, and how a family function can result in high achieved adolescents in school.

\section{Materials and Methods}

This research is an observational analytic study with a cross-sectional design to determine the correlation between family function and internet addiction, the correlation between family function and academic performance, and the correlation between internet addiction and academic achievement in adolescents at a particular time. Inclusion criteria include students in elected public high school who are willing to be included in the study by signing informed consent, living with both biological parents (nuclear family). Exclusion criteria include students in elected public high school who have physical illnesses of the brain (such as epilepsy) and mental disorders, do not fill out the questionnaire completely.

Before the study was conducted, validation of measurement tools was tested first: internet addiction using the Internet Addiction Test (IAT) and family functioning using the Family Assessment Device (FAD), which had been translated and modified into Indonesian. Internet addiction measuring instrument IAT became IAT-Ina, and family function measurement tool FAD became FAD-Ina after validation.

After the family function, internet addiction, and academic performance questionnaire has been adequate based on the number of samples that had been defined. The data were tabulated and analyzed by Windows 10 computer using SPSS 20 .

\section{Results}

The study was conducted on selected samples by random cluster sampling in 3 high schools in Denpasar. Total samples were 321 students, of which seven samples didn't fill out the questionnaire completely, and six samples did not live with both parents, so only 308 samples were left based on inclusion criteria in this study.

Of 130 men (43\%) and 175 women (57\%), the age ranged from 14 to 18 years old with an average age of 15.9 years. Based on the study major, there were more Natural Sciences students with 267 people $(87.6 \%)$ compared to Social Sciences with only 38 people $(12.4 \%)$.

Parents' occupations were mostly private employees (219 people, $71.7 \%$ ) followed by civil servants (60 people, 19.9\%). Academic performance is the total value of knowledge and skills of students from 16 subjects in school with a total mean value of 2,589.92.

Table 1. Characteristics of the subjects.

\begin{tabular}{lccccc}
\hline & N & \multicolumn{2}{c}{ Internet addiction } & \multicolumn{2}{c}{ Family function } \\
\cline { 3 - 6 } & & Yes & No & Good & Poor \\
\hline Money source & & & & & \\
Parents & $303(99.3)$ & $231(99.1)$ & $72(100)$ & $199(99)$ & $104(100)$ \\
$\quad$ Self & $2(0.7)$ & $2(0.9)$ & $0(0)$ & $2(1)$ & $0(0)$ \\
\hline Age at starting & & & & & \\
using internet & & & & & \\
$\quad$ 5-10 years & $80(26)$ & $65(27.9)$ & $14(19.4)$ & $51(25.4)$ & $28(26.9)$ \\
$\mathbf{1 1 - 1 5}$ years & $226(73.7)$ & $166(71.2)$ & $58(80.6)$ & $149(74.1)$ & $75(72.1)$ \\
$>\mathbf{1 5}$ years & $1(0.3)$ & $2(0.9)$ & $0(0)$ & $1(0.5)$ & $1(1)$ \\
\hline Online duration & & & & & \\
per day & & & & & \\
$\mathbf{0 - 5}$ hours & $95(31.1)$ & $75(32.2)$ & $21(29.2)$ & $59(29.4)$ & $36(34.6)$ \\
$\mathbf{5 - 1 0}$ hours & $108(35.4)$ & $74(31.8)$ & $34(47.2)$ & $75(37.3)$ & $33(31.7)$ \\
$\mathbf{1 0 - 1 5}$ hours & $70(23.0)$ & $56(24)$ & $14(19.4)$ & $44(21.9)$ & $26(25)$ \\
$\mathbf{1 6 - 2 0}$ hours & $26(8.5)$ & $23(9.9)$ & $3(4.2)$ & $20(9.9)$ & $6(5.8)$ \\
$>\mathbf{2 0}$ hours & $6(2)$ & $5(2.1)$ & $0(0)$ & $3(1.5)$ & $3(2.9)$ \\
\hline
\end{tabular}

The subjects started to go online on the internet since the age of 11.4 years $(73.7 \%)$ and the average online time of 8.86 hours in a day (35.4\%) and the least with more than 20 hours/day (2\%). The source of money used for online mostly was from parents (99.3\%) with 303 people (Table 1). Starting online age on average at the age of 11.47 years, mostly started at early adolescence at the age of 11-15 years as many as 226 people (73.7\%) people, followed by age 5-10 (26\%) and at 15 years or more $(0.3 \%)$.

The mean online duration per day was 8.82 hours, where adolescent mostly spent 6-10 hours (35.5\%), followed by $1-5$ hours (31.1\%), 11-15 hours (23\%), 16-20 hours (8.5\%), and more than 20 hours (2\%). A good family function was found in 201 subjects (65.9\%), and poor family function was found in 104 samples (34.1\%).

Table 2. Internet addiction.

\begin{tabular}{llll}
\hline Degree of internet addiction & Male & Female & Total \\
\hline No addiction & $29(22.3)$ & $43(24.6)$ & $72(23.6)$ \\
Mild & $91(70.0)$ & $120(68.5)$ & $211(69.2)$ \\
Moderate & $10(7.7)$ & $12(6.9)$ & $22(2.5)$ \\
Severe & $0(0)$ & $0(0)$ & $0(0)$ \\
\hline
\end{tabular}

The overall prevalence of internet addiction in high school students was $76.4 \%$ (Table 2). The degree of addiction is mostly mild internet addiction, with 211 people $(69.2 \%)$ and moderate internet addiction 
with 22 people (7.7\%). Mild internet addiction means the average internet users in the community, and they are able to control their behavior in using the internet. Moderate internet addiction means fairly frequent use of the internet and can cause problems for users. Intervention is immediately needed in this moderate internet addiction group because it can cause impairment in the daily function.

Family function simple linear regression test result shows there is a positive and significant correlation with internet addiction $(\mathrm{R}=0.336, \mathrm{p}<0.05)$. This means that the higher the family function score (worse family function) then, the higher the internet addiction score (more internet addiction) and vice versa, the lower the family function score (better family function) then, the lower the internet addiction score (less internet addiction).

Table 3. Family function linear regression test for internet addiction.

\begin{tabular}{lcccccc}
\hline \multicolumn{1}{c}{ Model } & $\mathbf{R}$ & $\mathbf{R}^{2}$ & $\boldsymbol{\beta}$ & $\begin{array}{c}\text { Adjusted } \mathbf{R} \\
\text { Square }\end{array}$ & $\begin{array}{c}\text { Std. } \\
\text { Error }\end{array}$ & $\mathbf{p}$ \\
\hline $\begin{array}{l}\text { Family function and } \\
\text { internet addiction }\end{array}$ & 0.336 & 0.113 & 0.336 & 0.110 & 9.492 & 0.000 \\
\hline
\end{tabular}

$\mathrm{R}^{2}=0.113$ means family function affects the occurrence of internet addiction for $11.3 \%$ and the rest $(88.7 \%)$ due to the influence of other factors (Table 3 ). $\mathrm{R}^{2}=0.031$ means that family function affects the academic performance for $3.1 \%$ and the rest $(96.9 \%)$ due to other factors. This result proves the hypothesis that good family function improves the academic performance of adolescents.

Table 4. Family function linear regression test for academic performance.

\begin{tabular}{lccccccc}
\hline Model & $\mathrm{R}$ & $\mathrm{R}^{2}$ & Beta & $\begin{array}{c}\text { Adjusted } \mathrm{R} \\
\text { Square }\end{array}$ & $\begin{array}{c}\text { Std. } \\
\text { Error }\end{array}$ & $\mathrm{p}$ \\
\hline Family function and & 0.176 & 0.031 & -0.176 & 0.028 & 70.526 & 0.002 \\
academic performance & & & & & & & \\
\hline
\end{tabular}

Results of internet addiction simple linear regression tests (Table 4) also show a positive and significant correlation for academic performance $(\mathrm{R}=0.128, \beta=0.128, \mathrm{p}<0.05)$. This means if the addiction score increases, then academic performance increases. Internet addiction hypothesis lowers academic performance is not proven in this study because the study did not measure the type of internet use. Perhaps the samples use the internet for matters related to education at school so that the internet can help the learning process that results in increased performance. It is certain that the value of R Square of 0.016 means that internet addiction affects $1.6 \%$ of academic performance.

\section{Discussion}

Internet technology has vast potential to improve educational opportunities in adolescents. Parents who do not control and guide the children cause the loss of children's abilities to perform and respond to the challenges of life, causing increased internet addiction and decreased academic performance. ${ }^{6,7}$

The same result was obtained in the study of Wu et al.1 that families that argue have low involvement, weak monitoring from both parents cause behavioral problems, where one of them is internet addiction. Social control theory states that when adolescents have a strong attachment to both parents and have positive family interaction, they will choose a path that won't be opposing. Otherwise, adolescents in families that often fight and have less attachment will refuse attention from parents.

This uncontrolled or pathologic internet usage can lead to negative consequences such as low to fail academic performance of adolescents, family conflict, and social conflict. Besides, internet addiction lowers the amount of face-to-face interaction, and this condition leads to social isolation and depression. An increased amount of time to be online makes adolescents have less time for more important activities such as doing schoolwork, following full school activities, etc.

The results of this study indicate that family function plays an important role in meeting the needs of adolescents and provides a behavior demand to optimally develop the potential of adolescents in this digital that is no different from parents throughout the ages. Adolescents continue to grow, and they want autonomy and freedom. The age of adolescence is a phase of searching for identity. 1

Research on parenting style indicates that a democratic parenting style in family function, where parents set clear rules and expectations and then discuss it with their children, make children happy, reliable, able to deal well with stress and achievement-oriented. ${ }^{7}$

Researchers consider family function, especially more communication from parents to children can prevent internet addiction and improve academic performance. ${ }^{1}$ It needs more research in the field of the internet, especially using the cohort method for quantitative and qualitative improvement. It is inevitable that the majority of internet users have behavior problems. ${ }^{6}$

\section{Conclusion}

The prevalence of internet addiction in adolescents in high school students was $76.4 \%$, which is a considerable large amount. Good family function lowers the internet addiction and improves academic performance in adolescents in order to improve the quality of the nation's youth.

\section{Acknowledgement}

The authors report no conflict of interests.

\section{Reference}

1. Wu CST, Wong HT, Yu KF, et al. Parenting approaches, family functionality, and internet addiction among Hong Kong adolescents. BMC Pediatr. 2016;16:130. DOI: 10.1186/s12887-0160666-y.

2. Sharma A, Sahu R, Kasar PK, et al. Internet Addiction among professional course students; a study from central India. International Journal of Medical Science and Public Health. 2014;3:9:1069-73. DOI: 10.5455/imjsph.2014.180620142. 
3. Zhang JT, Ma SS, Yip SW, et al. Decreased functional connectivity between ventral tegmental area and nucleus accumben in internet gaming disorder; evidence from resting state functional magnetic resonance imaging. Behav Brain Funct. 2015;11(1):37. DOI: 10.1186/s12993-0150082-8.

4. Peterrson R. Families first: keys to successful family functioning family roles. Available from: http://pubs.ext.vt.edu/350/350-093/350-093_pdf. pdf. Accessed on 5 January 2016.

5. Yen JY, Yen CF, Chen CC, et al. Family factors of internet addiction and substance use experience in Taiwanese adolescents. Cyberpsychol Behav. 2007 Jun;10(3):323-9. DOI: 10.1089/cpb.2006.9948
6. Cash H, Rae CD, Steel AH, et al. Internet Addiction: A Brief Summary of Research and Practice. Curr Psychiatry Rev. 2012;8(4):292-8. DOI: $10.2174 / 157340012803520513$

7. Wallace P. Internet addiction disorder and youth: There are growing concerns about compulsive online activity and that this could impede students' performance and social lives. EMBO Rep. 2014;15(1):12-16. DOI: $10.1002 / \mathrm{embr} .201338222$ 